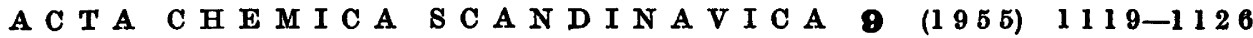

\title{
The Infrared Absorption of the Different Crystal Forms of Some Normal Fatty Acids
}

\author{
ERIK von S Y D O W \\ Institute of Chemistry, University of Uppsala, Uppsala, Sweden
}

\begin{abstract}
The infrared spectra of the different crystal forms of the same normal fatty acid are found to be different from each other. The parts of the spectra between 7.7 and $8.5 \mu$ (1 300 and $\left.1180 \mathrm{~cm}^{-1}\right)$ and near $11.0 \mu\left(900 \mathrm{~cm}^{-1}\right)$ are the best for identification purposes. In some cases the absorption near $5.9 \mu\left(1700 \mathrm{~cm}^{-1}\right)$, associated with the $\mathrm{C}=\mathrm{O}$ stretching vibration, has been found to consist of two close peaks.
\end{abstract}

Sinclair et al. ${ }^{1}$ and Bellamy ${ }^{2, p .149}$ have found that a considerable frequency shift occurs for the $\mathrm{OH}$ out-of-plane deformation when passing from the unstable crystalline B-form to the stable crystalline $\mathrm{C}$-form of $n$-stearic acid. In connection with crystal structure investigations of the different polymorphs of normal fatty acids, using single crystal and powder $X$-ray methods ${ }^{3-7}$, the infrared absorption between 5 and $13 \mu\left(2000 \mathrm{~cm}^{-1}\right.$ and $770 \mathrm{~cm}^{-1}$, respectively) of the different crystal forms has been measured, in order to find if there are any other differences. The acids investigated were $n$-pentadecanoic acid, $n$-palmitic acid and $n$-stearic acid.

\section{MATERIAL USED}

The very pure acids used have been prepared by Professor E. Stenhagen and his collaborators. The melting points of the $n$-pentadecanoic acid, $n$-palmitic acid and $n$-stearic acid are $52.3^{\circ} \mathrm{C}, 62.9^{\circ} \mathrm{C}$ and $69.7^{\circ} \mathrm{C}$, respectively.

There are three polymorphs of acids with an even number of carbon atoms and three of acids with an odd number of carbon atoms ${ }^{3}$.

The $A^{\prime}$-form of $n$-pentadecanoic acid was crystallized from petroleum (b. p. $40^{\circ}-$ $\left.60^{\circ} \mathrm{C}\right)^{3}$.

The $B^{\prime}$-form of the same acid was crystallized from the melt ${ }^{3}$.

The crystal structure of both forms have been described by the author 4,5 .

The C'-form of the same acid can only exist between $46^{\circ} \mathrm{C}$ and the melting point ${ }^{3}$ and it was crystallized from the melt by lowering the temperature just under the melting point. The crystal structure of the $C^{\prime}$-form of $n$-hendecanoic acid is being investigated at present by the author.

Acta Chem. Scand. 9 (1955) No. 7 
Table 1. Infrared absorption of normal fatty acids near $5.9 \mu\left(1700 \mathrm{~cm}^{-1}\right), 7.0 \mu\left(1400 \mathrm{~cm}^{-1}\right)$ and $11.0 \mu\left(900 \mathrm{~cm}^{-1}\right)$. Upper values wavelength $(\mu)$, lower values wavenumber $\left(\mathrm{cm}^{-1}\right)$. $(\mathrm{sh})=$ shoulder.

\begin{tabular}{|c|c|c|c|c|c|c|c|}
\hline \multirow[b]{2}{*}{ Fig. } & \multirow{2}{*}{$\begin{array}{l}\text { Number } \\
\text { of carbon } \\
\text { atoms in } \\
\text { the acid }\end{array}$} & \multirow{2}{*}{$\begin{array}{l}\text { Crystal } \\
\text { form }\end{array}$} & \multicolumn{2}{|c|}{$\begin{array}{c}\text { Near } 5.9 \mu \\
\left(1700 \mathrm{~cm}^{-1}\right)\end{array}$} & \multirow{2}{*}{$\begin{array}{l}\text { Near } \\
7.0 \mu \\
(1400 \\
\left.\mathrm{cm}^{-1}\right)\end{array}$} & \multicolumn{2}{|c|}{ Near $11.0 \mu\left(900 \mathrm{~cm}^{-1}\right)$} \\
\hline & & & $\begin{array}{l}\text { Maxi- } \\
\text { mum } \\
\text { absorp- } \\
\text { tion }\end{array}$ & $\begin{array}{l}\text { "Mean } \\
\text { value" } \\
\text { (see } \\
\text { text) }\end{array}$ & & $\begin{array}{l}\text { Maxi- } \\
\text { mum } \\
\text { absorp- } \\
\text { tion }\end{array}$ & Other values \\
\hline 1 & 15 & $\mathbf{A}^{\prime}$ & $\begin{array}{l}5.840 \\
1712\end{array}$ & $\begin{array}{l}5.860 \\
1706\end{array}$ & $\begin{array}{l}7.075 \\
1413\end{array}$ & $\begin{array}{c}10.745 \\
931\end{array}$ & $\begin{array}{ccc}11.235 & 11.71 & (\mathrm{sh}) \\
890 & 854 & \end{array}$ \\
\hline 2 & 15 & $\mathrm{~B}^{\prime}$ & $\begin{array}{l}5.840 \\
1712\end{array}$ & $\begin{array}{l}5.865 \\
1705\end{array}$ & $\begin{array}{l}7.090 \\
1410\end{array}$ & $\begin{array}{c}10.780 \\
928\end{array}$ & $\left|\begin{array}{ccc}10.42 & (\mathrm{sh}) & 10.96(\mathrm{sh}) \\
960 & 912 \\
11.20 & (\mathrm{sh}) & 11.40(\mathrm{sh}) \\
893 & 877 & 877\end{array}\right|$ \\
\hline 3 & 15 & $\mathbf{C}^{\prime}$ & $\begin{array}{l}5.845 \\
1711\end{array}$ & $\begin{array}{l}5.860 \\
1706\end{array}$ & $\begin{array}{l}7.090 \\
1410\end{array}$ & $\begin{array}{c}10.720 \\
933\end{array}$ & $\begin{array}{c}11.20 \\
893\end{array}(\mathrm{sh})$ \\
\hline 4 & 15 & melt & $\begin{array}{l}5.850 \\
1709\end{array}$ & $\begin{array}{l}5.850 \\
1709\end{array}$ & $\begin{array}{l}7.095 \\
1409\end{array}$ & $\begin{array}{c}10.765 \\
929\end{array}$ & \\
\hline 5 & 16 & $\mathbf{A}$ & $\begin{array}{l}5.885 \\
1699\end{array}$ & $\begin{array}{r}5.890 \\
1698\end{array}$ & $\begin{array}{l}7.100 \\
1408\end{array}$ & $\begin{array}{c}10.695 \\
935\end{array}$ & 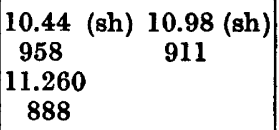 \\
\hline 6 & 16 & $\mathbf{C}$ & $\begin{array}{l}5.840 \\
1712\end{array}$ & $\begin{array}{l}5.880 \\
1701\end{array}$ & $\begin{array}{l}7.080 \\
1412\end{array}$ & $\begin{array}{c}10.650 \\
939\end{array}$ & \begin{tabular}{|cc}
$10.50(\mathrm{sh})$ & 11.235 \\
952 & 890 \\
11.770 & \\
850 & \\
\end{tabular} \\
\hline 7 & 18 & B & $\begin{array}{l}5.845 \\
1711 \\
5.910 \\
1692\end{array}$ & $\begin{array}{l}5.880 \\
1701\end{array}$ & $\begin{array}{l}7.130 \\
1403\end{array}$ & $\begin{array}{c}11.275 \\
887\end{array}$ & $\begin{array}{cc}10.63(\mathrm{sh}) & 10.950 \\
941 & 913 \\
11.440 & 11.775 \\
874 & 849\end{array}$ \\
\hline 8 & 18 & $\mathbf{C}$ & $\begin{array}{l}5.865 \\
1705\end{array}$ & $\begin{array}{l}5.880 \\
1701\end{array}$ & $\begin{array}{l}7.070 \\
1414\end{array}$ & $\begin{array}{c}10.625 \\
941\end{array}$ & $\begin{array}{ccc}10.50 & (\mathrm{sh}) & 11.225 \\
952 & & 891 \\
11.77 & (\mathrm{sh}) & \\
850 & & \end{array}$ \\
\hline 9 & 16 & melt & $\begin{array}{l}5.860 \\
1706\end{array}$ & $\begin{array}{l}5.850 \\
1709\end{array}$ & $\begin{array}{l}7.080 \\
1412\end{array}$ & $\begin{array}{c}10.690 \\
935\end{array}$ & \\
\hline
\end{tabular}

It was not possible to prepare pure A-, B- and C-forms of the same acid with an even number of carbon atoms. Thus two acids were used and the polymorphs were prepared in the following way.

The A-form of palmitic acid was crystallized from petroleum (b. p. $40^{\circ}-60^{\circ} \mathrm{C}$ ) ${ }^{3}$. The same crystal form of lauric acid is being investigated at present using single crystal X-ray methods.

The B-form of stearic acid was crystallized from petroleum (b.p. $40^{\circ}-60^{\circ} \mathrm{C}$ ) ?. Its crystal structure has been previously described?

The C-forms of palmitic and stearic acid were crystallized from the melt ${ }^{3}$. The Cform of lauric acid has been described by Vand, Morley and Lomer ${ }^{8}$. 
Table 2. Infrared absorption of normal fatty acids between 7.7 and $8.5 \mu\left(1300\right.$ and $\left.1180 \mathrm{~cm}^{-1}\right)$. Upper values wavelength $(\mu)$, lower values wavenumber $\left(\mathrm{cm}^{-1}\right)$.

\begin{tabular}{|c|c|c|c|c|c|}
\hline Fig. & $\begin{array}{l}\text { Number } \\
\text { of carbon } \\
\text { atoms in } \\
\text { the acid }\end{array}$ & $\begin{array}{c}\text { Crys- } \\
\text { tal } \\
\text { form }\end{array}$ & Band progression & $\begin{array}{l}\text { Near } \\
7.81 \mu \\
(1280 \\
\left.\mathrm{cm}^{-1}\right)\end{array}$ & $\begin{array}{l}\text { Near } \\
8.07 \mu \\
(1239 \\
\left.\mathrm{cm}^{-1}\right)\end{array}$ \\
\hline 1 & 15 & $\mathbf{A}^{\prime}$ & 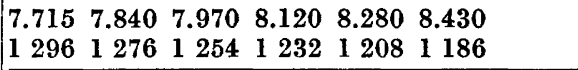 & & \\
\hline 2 & 15 & $\mathbf{B}^{\prime}$ & 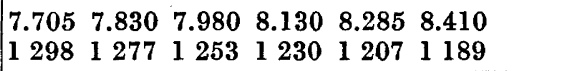 & & \\
\hline 3 & 15 & $\mathbf{C}^{\prime}$ & & $\begin{array}{l}7.810 \\
1280\end{array}$ & $\begin{array}{l}8.065 \\
1240\end{array}$ \\
\hline 4 & 15 & melt & & $\begin{array}{l}7.800 \\
1282\end{array}$ & $\begin{array}{l}8.060 \\
1241\end{array}$ \\
\hline 5 & 16 & $\mathbf{A}$ & 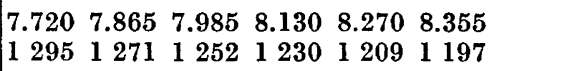 & & \\
\hline 6 & 16 & C & 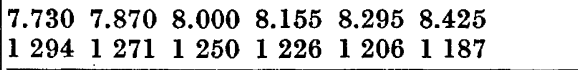 & & \\
\hline 7 & 18 & B & 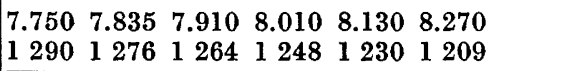 & & \\
\hline 8 & 18 & C & 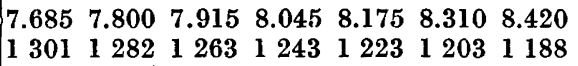 & & \\
\hline 9 & 16 & melt & & $\begin{array}{l}7.810 \\
1280\end{array}$ & $\begin{array}{l}8.090 \\
1236\end{array}$ \\
\hline
\end{tabular}

\section{EXPERIMENTAL}

A Perkin Elmer model 21 spectrophotometer with sodium chloride prism was used for the infrared absorption measurements. The specimens were investigated as nujol mulls. The temperature in the sample holder was $36^{\circ} \mathrm{C}$ without extra heating. In the cases where higher temperatures were necessary the sample holder was equipped with a thermometer and isolated with asbestos thread and heated with a heating lamp to the right temperature. All absorption curves, which are linear in wavelength, were calibrated with a polystyrene spectrum and the values are exact up to $\pm 0.01 \mu$.

\section{RESULTS AND DISCUSSION}

All polymorphs mentioned above as well as liquid $n$-pentadecanoic acid and $n$-palmitic acid were investigated. The absorption curves can be seen in Figs. 1-9 and the wavelengths measured in Table 1 and 2.

The following parts of the spectra are of special interest and will be discussed one by one: near $5.9 \mu\left(1700 \mathrm{~cm}^{-1}\right)$, near $7.0 \mu\left(1400 \mathrm{~cm}^{-1}\right)$, band progression $7.7-8.5 \mu\left(1300-1180 \mathrm{~cm}^{-1}\right)$ and near $11.0 \mu\left(900 \mathrm{~cm}^{-1}\right)$. 


\section{Ne a r $5.9 \mu \quad\left(1700 \mathrm{~cm}^{-1}\right)$}

There is a strong absorption peak near $5.9 \mu\left(1700 \mathrm{~cm}^{-1}\right)$ which has been attributed to the $\mathrm{C}=\mathrm{O}$ stretching vibration in dimers. Davies and Sutherland ${ }^{\circ}$ point out that this peak and that belonging to the probable $\mathrm{C}=0$ stretching vibration at $7.81 \mu\left(1280 \mathrm{~cm}^{-1}\right)$ should be double, owing to the dimerization resulting from hydrogen bonding of two carboxylic groups.

In the case of the B-form of stearic acid the peak is clearly resolved into two peaks at $5.845 \mu\left(1711 \mathrm{~cm}^{-1}\right)$ and $5.910 \mu\left(1692 \mathrm{~cm}^{-1}\right)$ of the same heights (Fig. 7 and Table 1) and in some of the other cases shoulders can be seen indicating more than one absorption peak. The occurrence of this double peak might also indicate the presence of two different $\mathrm{C}=\mathrm{O}$ bonds in the crystals of this polymorph but this is not the case ${ }^{7}$, so this possibility can be ruled out.

In order to be able to compare the wavelengths with previous results use has been made of a "mean value" which is the wavelength that cuts the whole area of the absorption peak in two equal parts. These "mean values" and the values for maximum absorption are found in Table 1. The "mean values" agree very well with those measured by Sinclair et al. ${ }^{1}$ and others. It can be seen that all the values for maximum absorption and all the "mean values" lie on or between the two values found for the crystalline B-form of stearic acid. There may possibly be two peaks at these wavelengths in all cases but as their relative intensities may be different the values for maximum absorption and "mean values" may vary between the extreme values.

$$
\text { Near } 7.0 \mu \quad\left(1400 \quad \mathrm{~cm}^{-1}\right)
$$

There is an absorption peak between $7.07 \mu$ and $7.13 \mu\left(1414 \mathrm{~cm}^{-1}\right.$ and $1403 \mathrm{~cm}^{-1}$ ) (Table 1) which has been associated with the deformation of the first $\mathrm{CH}_{2}$ group which is influenced by the carboxylic group ${ }^{2, p .147}$.

In Fig. 3 in the paper by Sinclair et al. ${ }^{1}$ it can be seen that the position of this peak depends also on the chain-length. As both chain-length and crystal form can vary for the fatty acids this absorption peak alone cannot be used for identification.

$$
\text { Band progression 7.7-8.5 } \mu\left(1300-1180 \mathrm{~cm}^{-1}\right)
$$

Jones et $a l .^{10}$ point out that the number and positions of the evenly spaced absorption peaks in this interval are dependent on the chain-length. These absorption wavelengths have been associated with twisting and wagging motions of the methylene groups in the hydrocarbon chains.

In Table 2 it can be seen, that the positions of the peaks are also dependent on the crystal form. The wavelength values for the B-form of stearic acid compared with the $\mathrm{C}$-form of the same acid are higher at lower wavelengths and lower at higher wavelengths in this interval. A comparison between the A- and C-forms of palmitic acid reveals that at lower wavelengths the absorption peaks have the same positions, but that at higher wavelengths the values belonging to the A-form are shifted to shorter wavelengths.

The $A^{\prime}$ - and $B^{\prime}$-forms of $n$-pentadecanoic acid do not show any difference in this region. 

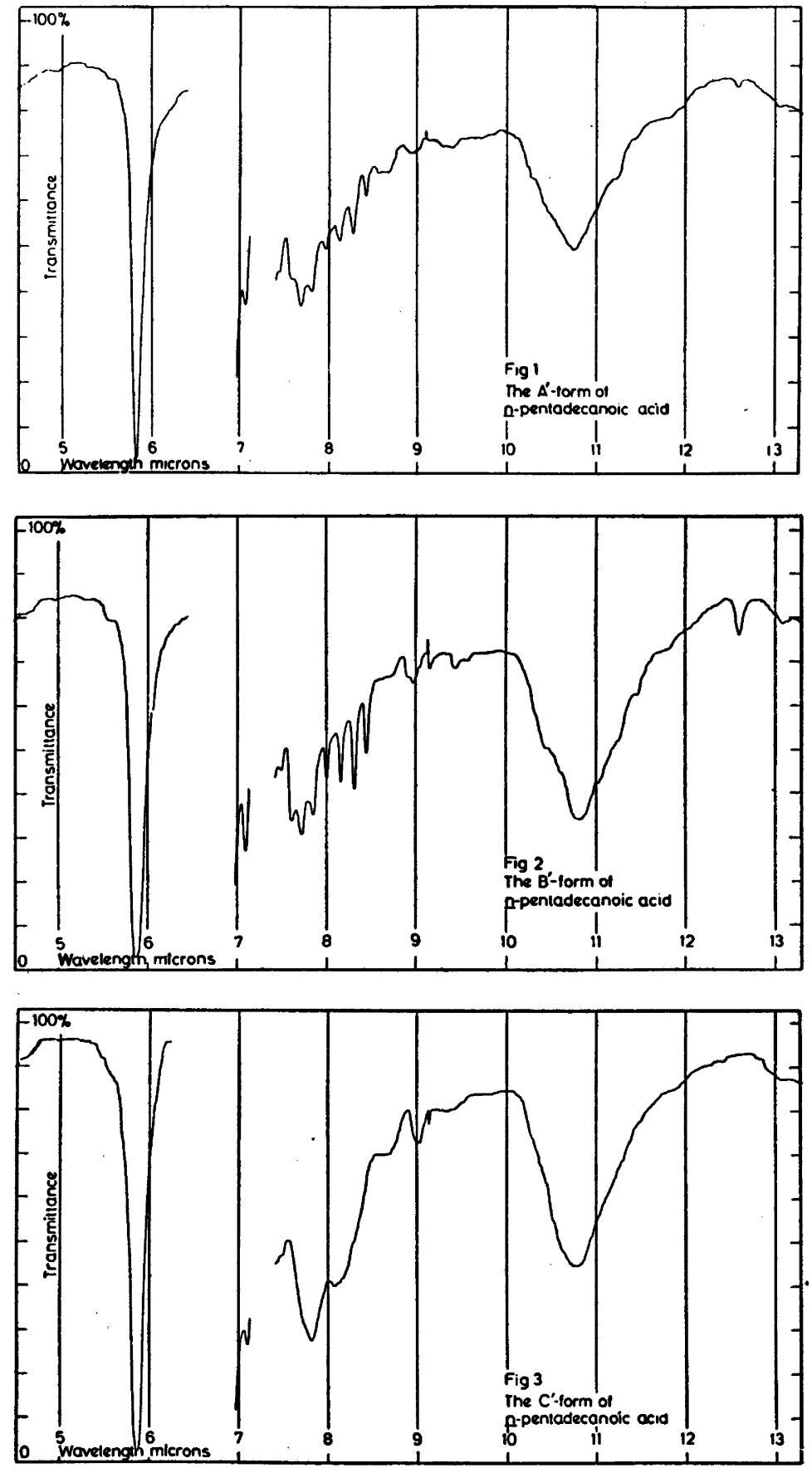

Acta Chem. Scand. 9 (1955) No. 7 

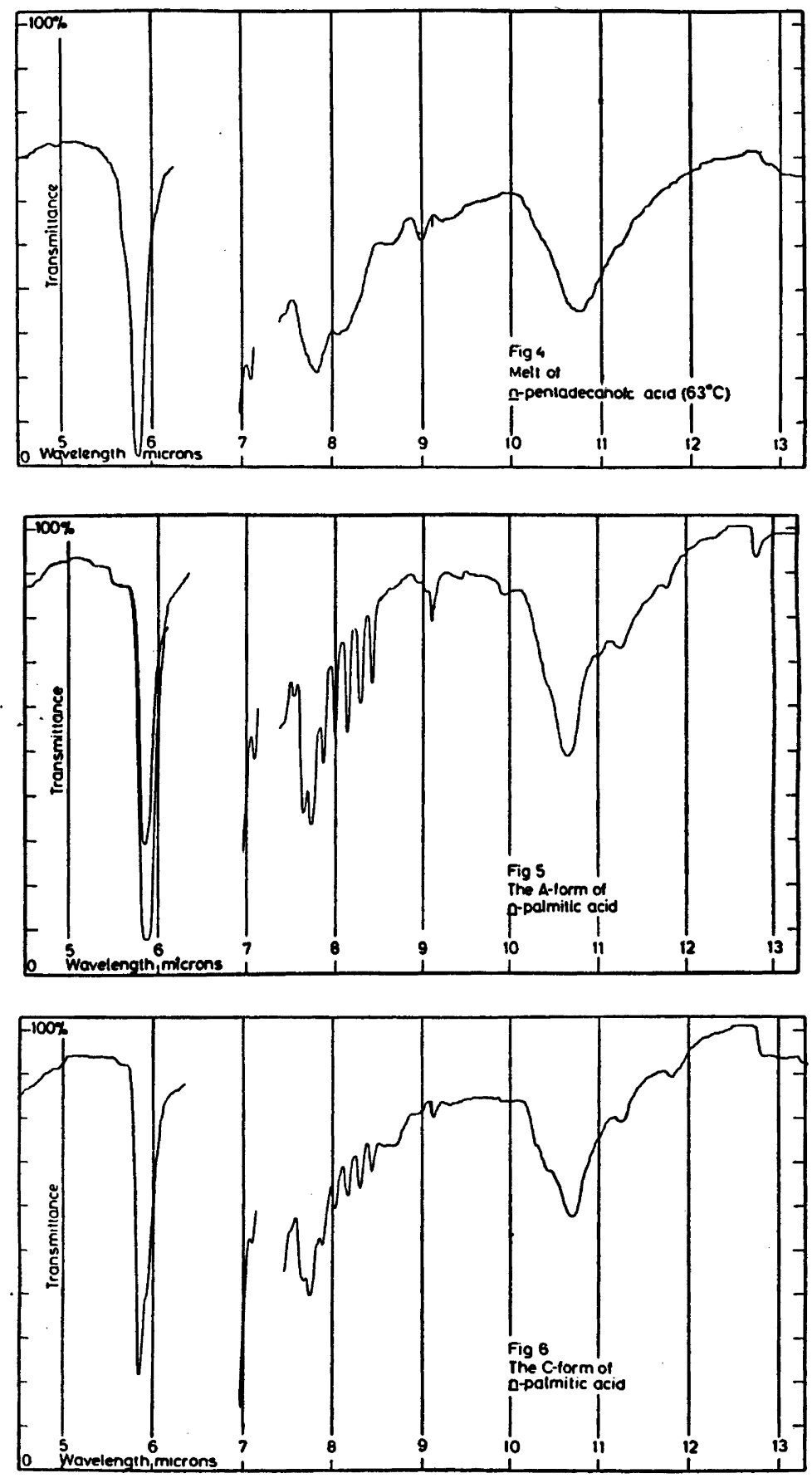

Acta Chem. Scand. 9 (1955) No. 7 

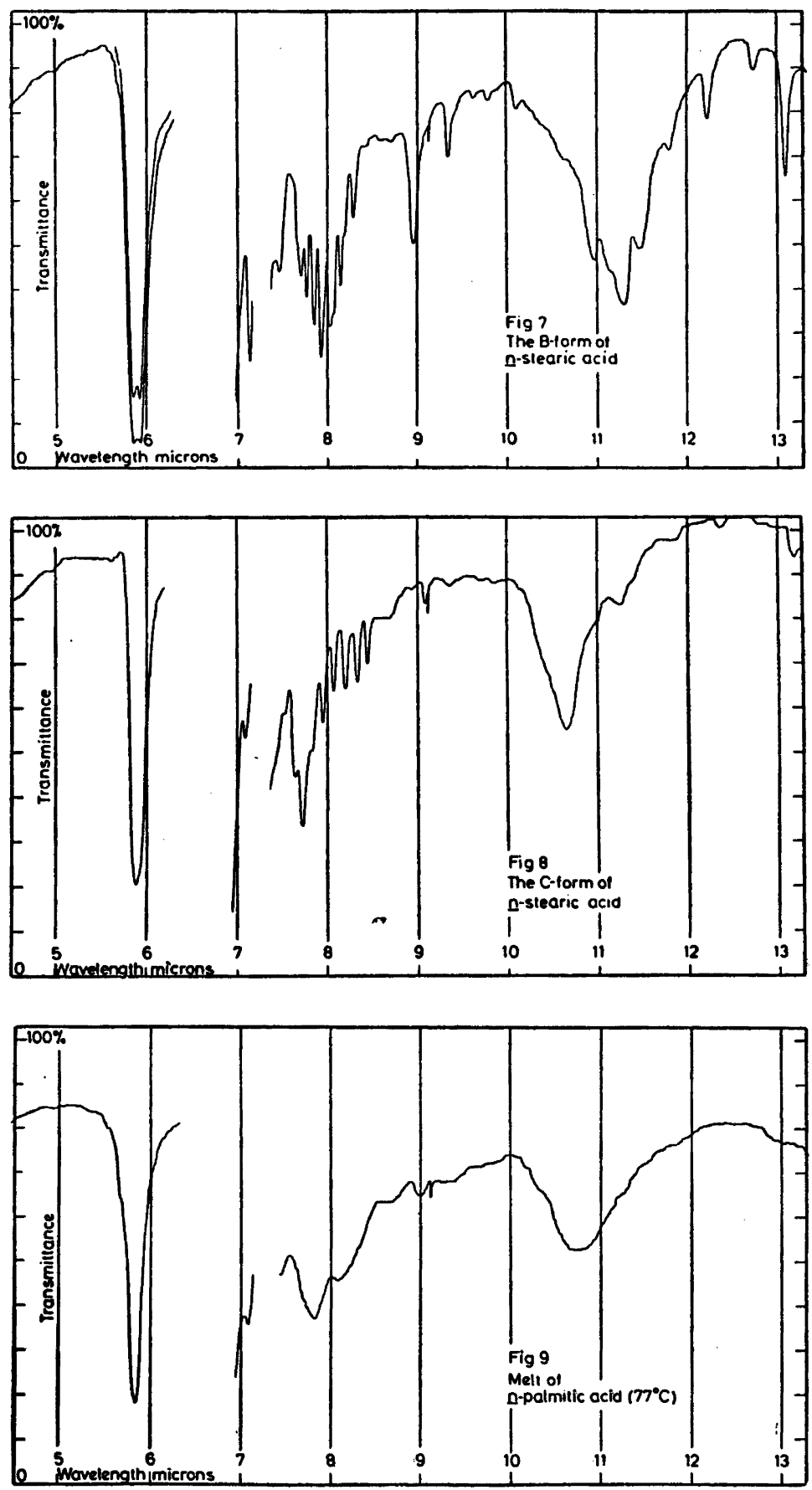

Acta Chem. Scand. 9 (1955) No. 7 
The $C^{\prime}$-form and the melt of $n$-pentadecanoic acid as well as the melt of palmitic acid do not show this band progression. Bellamy ${ }^{2, p .149}$ says, however, that even in the liquid state normal fatty acids exhibit this band progression. In a private communication he says that the melted films examined had been re-solidified thus having some degree of orientation.

I think it is rather probable that when the thermal motion increases, the twisting and wagging motions become less regular and there will be no sharp absorption at special wavelengths near and over the melting point.

The spectra of the $\mathrm{C}^{\prime}$-form and the melt of $n$-pentadecanoic acid as well as the melt of palmitic acid have, however, two peaks at $7.81 \mu\left(1280 \mathrm{~cm}^{-1}\right)$ and $8.07 \mu\left(1239 \mathrm{~cm}^{-1}\right)$. Their origins are very uncertain but they certainly have something to do with the carboxylic group.

$$
\text { Near } 11.0 \mu\left(900 \mathrm{~cm}^{-1}\right)
$$

There is an absorption region near $11.0 \mu\left(900 \mathrm{~cm}^{-1}\right)$ which has been associated with the $\mathrm{OH}$ out-of-plane deformation ${ }^{11}$.

The values for the different crystal forms and melts are tabulated in Table 1. The absorption region consists either of a broad peak with several shoulders and smaller peaks or of a couple of more narrow peaks. The exact origin of all these peaks is very uncertain. However, as no two crystal forms have the same absorption this part of the infra-red spectra is very suitable for identification, particularly in combination with studies of the band progression between 7.7 and $8.5 \mu$ (1 300 and $\left.1180 \mathrm{~cm}^{-1}\right)$.

In the work by Sinclair et al. ${ }^{1}$, Fig 3 , it can be seen that the value for maximum absorption near $11.0 \mu\left(900 \mathrm{~cm}^{-1}\right)$ is constant for the same crystal form of acids with 14, 16, 18 and 20 carbon atoms (the C-form) and of acids with 17, 19 and 21 carbon atoms (the $B^{\prime}$-form), respectively.

The melted acids have very broad absorption peaks without any shoulders or extra peaks.

Acknowledgement. I am indebted to Professor Arne Tiselius for permission to use the spectrophotometer and to Mr. Andreas Rosenberg for his interest and valuable advice during the work. I am also thankful to Professors Gunnar Hägg and Einar Stenhagen for their great interest and to Mr. Stig Bergwall for technical assistance.

\section{REFERENCES}

1. Sinclair, R. G., McKay, A. F. and Jones, R. N. J. Am. Chem. Soc. 74 (1952) 2570.

2. Bellamy, L. J. The Infra-red Spectra of Complex Molecules, London 1954.

3. Stenhagen, E. and von Sydow, E. Arkiv Kemi 6 (1953) 309.

4. von Sydow, E. Acta Cryst. 7 (1954) 529.

5. Abrahamsson, S. and von Sydow, E. Acta Cryst. 7 (1954) 591.

6. von Sydow, E. Acta Cryst. 7 (1954) 823.

7. von Sydow, E. Acta Cryst. In press.

8. Vand, V., Morley, W. M. and Lomer, T. R. Acta Cryst. 4 (1951) 324.

9. Davies, M. M. and Suthorland, G. B. B. M. J. Chem. Phys. 6 (1938) 755.

10. Jones, R. N., Mc Kay, A. F. and Sinclair, R. G. J. Am. Chem. Soc. 74 (1952) 2575.

11. Hadži, D. and Sheppard, N. Proc. Roy. Soc. London A 216 (1953) 247.

Received April 29, 1955.

Acta Chem. Scand. 9 (1955) No. 7 